\title{
A esquizoanálise: um olhar oblíquo sobre corpos, gêneros e sexualidades
}

\author{
Nilson FERnANDES Dinis \\ Doutor em Educação \\ Professor da UFSCAR \\ ndinis@ufscar.br
}

\begin{abstract}
Resumo O trabalho apresenta alguns conceitos da esquizoanálise, teoria produzida por Gilles Deleuze e Félix Guattari, para analisar algumas das cartografias contemporâneas sobre as novas estéticas do corpo, de gênero e da sexualidade. O projeto esquizoanalítico apresenta o desafio da desconstrução dos modelos monolíticos da subjetividade para uma produção de novas estéticas da subjetividade e novas semióticas, que reinventem novas relações com os outros e com nós mesmos, na composição de novos territórios existenciais. O desafio de uma experimentação que leve em conta não identidades, mas devires, não retrospectros do passado, mas o próprio presente, ensaiando novas formas de subjetividade, novas estéticas da existência.
\end{abstract}

Palavras-chave: esquizoanálise; corpo; gênero; sexualidade.

$\mathrm{O}$ BLÍQuo: “(Do lat. Obliquu). Adj. 1. Não perpendicular; inclinado; de través (...) 2. Torto; vesgo 3. Fig. Indireto. 4. Malicioso; dissimulado, ardiloso; sinuoso ...”(Ferreira, 1986, p. 1.209). Oblíquo talvez seja um adjetivo que se aplique bem ao olhar cartográfico da Esquizoanálise. Um olhar que propõe resistência ao olhar perpendicular das práticas psicológicas de diagnóstico, o olhar da anamnese com suas linhas retas de causa e efeito, um procedimento que captura multiplicidades de sensações em um único fio narrativo, compondo corpos estratificados, estáveis, portanto, previsíveis.

Como ressalta Rolnik (1989, p.15) as paisagens psicossociais também são cartografáveis, mas diferentemente das linhas estáveis dos mapas, formam um desenho que vai se fazendo e refazendo com os acontecimentos: a cartografia, neste caso, acompanha e se faz ao mesmo tempo o desmanchamento de certo mundos - sua perda de sentido - e a formação de outros: mundos que se criam para expressar afetos contemporâneos, em relação aos quais os universos vigentes tornaram-se obsoletos (Rolnik,1989, p.15).

O olhar do cartógrafo nos lembra também o olhar do estrangeiro, expressão utilizada por Nelson Brissac Peixoto, para falar desse personagem bastante presente nas imagens cinematográficas que

...não é do lugar, que acabou de chegar, é capaz de ver aquilo que os que lá estão não podem mais perceber [...] é capaz de olhar as coisas como se fosse pela primeira vez e de viver histórias originais. Todo um programa se delineia aí: livrar a paisagem da representação que se faz dela, retratar sem pensar em nada já visto antes. Contar histórias simples, respeitando os detalhes, deixando as coisas aparecerem como são (Peixoto, 1988, p. 363).

Também nos lembra o olhar da criança, olhar que vê o mundo com uma mistura de estupefação, admiração, estranhamento e curio- 
sidade insaciável, dissolvendo a ordem estabelecida do convencional e do habitual mediante o espaço lúdico da reinvenção.

Entretanto, o que seria a esquizoanálise? Esquizo-análise, rizoma-análise, análise micro-política, análise pragmática, filosofia da diferença, clínica da diferença. Muitos signos são utilizados para apreender o trabalho filósofico dos franceses Gilles Deleuze e Félix Guattari. Como ressalta Machado (1990), o trabalho de Deleuze e Guattari nasce de um sistema de colagem, ou melhor dizendo de bricolage de várias teorias filosóficas. Os estóicos, Leibniz, Spinoza e Nietzsche têm lugar proeminente. No entanto também entram em articulação com a literatura, a pintura, a música ou mesmo o cinema. Ao invés de mero sincretismo, o objetivo principal é extrair de cada módulo o potencial de diferença, motor propulsor da filosofia de Deleuze e Guattari.

Gilles Deleuze (1925-1995), professor de história da filosofia. Félix Guattari (1930-1992), psicanalista e ativista político. Um encontro entre estes dois autores que no fim da década de 1960 produz a esquizoanálise. $\mathrm{Na}$ tentativa de romper com os paradigmas da psicanálise e do marxismo, predominantes na década de 1960 na França, as noções de Inconsciente e Subjetividade serão reformuladas. A noção de 'inconsciente maquínico' em Guattari rompe com o inconsciente freudiano da Representação. $O$ inconsciente não é mais o teatro de Édipo, é usina, máquina de produção. $\mathrm{O}$ inconsciente é maquínico, não porque tenha a ver com máquinas, mas porque é produzido com base em componentes mais heterogêneos. Ele é algo produzido no real-social e atravessa os indivíduos, suas relações e seus territórios. Não é um inconsciente voltado para o passado, mas essencialmente ligado às composições atuais. O inconsciente é o campo de imersão do Desejo no campo social, é algo a ser constantemente produzido.

Há muito tempo recusei o dualismo consciente-inconsciente das tópicas freudianas e todas as oposições maniqueístas correlativas à triangulação edipiana, ao complexo de castração etc. Optei por um inconsciente que superpõe múltiplos estratos de subjetivações, estratos heterogêneos, de extensão e de consistência maiores ou menores. Inconsciente, então, mais 'esquizo', liberado dos grilhões familialistas, mais voltado para práxis atuais do que para fixações e regressões em relação ao passado. Inconsciente de Fluxo e de máquinas abstratas, mais do que inconsciente de estrutura e de linguagem (Guattari, 1992, p. 23).

As proposições deste inconsciente, longe de serem universais, são sempre singulares, fugindo às garras de um reducionismo cientificista. As identidades e as trajetórias serão sempre relativas num perpétuo movimento de desterritorialização e (re)territoriali- zação. E a Subjetividade longe de remeter a um Eu, é sempre múltipla. Isso é um fator que explica o fascínio dos autores por alguns dos processos de dissociação produzidos pela esquizofrenia.

Portanto, a idéia de uma subjetividade múltipla ou polifônica, como a define Guattari (1992), afirma um exercício de composição de uma subjetividade produzida pelos elementos mais heterogêneos, um exercício otimista de afirmação da vida, que aproxima-se muito da criação artística. A literatura está rica de exemplos. Não é atoa que um dos textos de Deleuze chama-se justamente Crítica e Clínica. Exemplos da literatura também percorrem os principais livros que resultaram de sua parceria com Félix Guattari: o AntiÉdipo e Mil Platôs. Tanto na literatura como na vida, há sempre o desafio de desmanchar o eu em direção à multiplicidade de afectos e sensações. Não há literatura sem fabulação, mas, como Bergson soube vê-lo, a fabulação, a função fabular não consiste em imaginar nem projetar um eu. Ela atinge sobretudo essas visões, eleva-se até esses devires ou potências (Deleuze, 1997, p. 13). Essas cartografias também aparecem na literatura brasileira, a exemplo das cartografias existenciais produzidas pela escritora Clarice Lispector. Uma das primeiras personagens clariceanas, Joana, em Perto do Coração Selvagem, já possui uma forma bem singular de perceber e viver seu corpo:

Seu rosto era leve e impreciso, boiando entre os outros rostos opacos e seguros, como se ele ainda não pudesse adquirir apoio em qualquer expressão. Todo o seu corpo e a sua alma perdiam os limites, misturavam-se, fundiamse num só caos, suave e amorfo, lento e de movimentos vagos como matéria simplesmente via. Era a renovação perfeita, a criação (Lispector, 1980, p. 92-93).

O romance, que descreve a lógica das sensações vividas por Joana, a principal personagem, torna-se quase um tratado sobre o corpo, já que o assunto retorna em várias passagens. Um corpo móvel, mutante, percorrido por intensidades, e não pelos contornos que definem um organismo. Joana vive seu corpo com um estado de fluidez que a condena à imprecisão. Vivendo este corpo sempre a devir, o encontro de Joana com o espelho só podia ser um encontro de estranhamento:

Quando me surpreendo ao fundo do espelho assustome. Mal posso acreditar que tenho limites, que sou recortada e definida. Sinto-me espalhada no ar, pensando dentro das criaturas, vivendo nas coisas além de mim mesma. Quando me surpreendo ao espelho não me assusto porque me ache feia ou bonita. É que me descubro de outra qualidade. Depois de não me ver há muito quase esqueço que sou humana, esqueço o meu passado e sou com a mesma libertação de fim e de consciência quanto uma coisa apenas viva (Lispector, 1980, p. 62). 
Se nesse momento, frente ao espelho, Joana ousasse se perguntar "quem eu sou?", provavelmente responderia como Alice responde à Lagarta, no país das maravilhas, de Lewis Carroll (1972, p.21): "Para falar a verdade, ignoro. Quando me levantei esta manhã, eu sabia quem eu era; mas durante o dia mudei tanto que não sei mais quem sou."

Talvez a frase de Spinoza, citada tanto por Deleuze, como por Clarice Lispector, em Perto do Coração Selvagem, possa nos ajudar a compreender um dos conceitos principais da ezquizoanálise - o conceito de corpo sem órgãos: Os corpos se distinguem uns dos outros em relação ao movimento e ao repouso, à velocidade e à lentidão e não em relação à substância (Lispector, 1980, p.115-116). A pergunta espinozista sobre o que pode um corpo, era uma das questões que mais atraiam Deleuze e Guattari na filosofia de Spinoza, e pode traduzir algumas das experimentações com o corpo preconizadas na esquizoanálise.

O conceito de corpo sem órgãos foi criado por Deleuze e Guattari com base em diversas fontes: do conceito de substância em Spinoza, de um poema de Artaud, do conceito de corpo tântrico das religiões hinduístas e também do conceito de ovo cósmico da comunidade Dogon. Em comum estes diversos corpos se caracterizam por sua composição, que envolve diferentes fluxos cruzando diversos eixos, e distribuindose em gradientes, que, por fim, compõem áreas energéticas móveis que se caracterizam por diversos graus de intensidade. Nesse sentido, o conceito de corpo sem órgãos é uma defesa ativa e eficaz contra os modelos de subjetivação que tornaram-se predominantes na modernidade ocidental: o sujeito e a identidade.

Isso nos possibilita entender o corpo, não como uma essência, mas como o resultado de uma conjunção de forças e circunstâncias, permitindo, até mesmo, outros modos de individuação que não remetam à idéia de identidade ou de sujeito. Porém o corpo sem órgãos não se opõe aos órgãos, mas à idéia de um organismo, pois é composto de matérias não formadas e energias não vetorizadas como forças, no entanto, as intensidades, circulando por ele, configuram as máquinas desejantes e suas conexões capazes de gerar os elementos mais heterogêneos. Já o organismo,

... não é o corpo, o $\mathrm{CsO}$, mas um extrato sobre o $\mathrm{CsO}$, quer dizer um fenômeno de acumulação, de coagulação, de sedimentação que lhe impõe formas, funções, ligações, organizações dominantes e hierarquizadas, transcendências organizadas para extrair um trabalho útil [...] O $\mathrm{CsO}$ grita: fizeram-me um organismo! dobraram-me indevidamente! roubaram meu corpo! O juízo de Deus arranca-o de sua imanência, e lhe constrói um organismo, uma significação, um sujeito. É ele o estratificado. Assim, ele oscila entre dois pólos: de um lado, as superfícies de estratificação sobre as quais ele é rebaixado e submetido ao juízo, e, por outro lado, o plano de consistência no qual ele se desenrola e se abre à experimentação (Deleuze; Guattari, 1996, p. 21, v.3).

No entanto como criar para si um corpo sem órgãos?, pergunta que nomeia um dos capítulos de Mil Platôs.

Onde a psicanálise diz: Pare, reencontre seu eu, seria preciso dizer: vamos mais longe, não encontramos ainda nosso $\mathrm{CsO}$, não desfizemos ainda suficientemente nosso eu. Substituir a anamnese pelo esquecimento, a interpretação pela experimentação (Deleuze; Guattari, 1996, p. 11, v.3).

Ou seja, desarticular, desfazer o organismo, abrir o corpo a conexões, passagens e distribuições de intensidade as mais heterogêneas. Um trabalho que, como ressaltam os autores, não se faz com pancadas de martelo, mas com uma lima muito fina, enfim, com uma dose de prudência, para que o processo de experimentação não leve a uma linha de loucura ou de morte.

Liberem-no com um gesto demasiado violento, façam saltar os estratos sem prudência e vocês mesmo se matarão, encravados num buraco negro, ou mesmo envolvidos numa catástrofe, ao invés de saltar o plano. O pior não é permanecer estratificado - organizado, significado, sujeitado - mas precipitar os estratos numa queda suicida ou demente, que os faz recair sobre nós, mais pesados do que nunca (Deleuze; Guattari, 1996, p. $23-24$, v.3).

A arte das doses e o perigo da overdose. Limite entre o remédio e o veneno. Fazer um corpo sem órgãos é uma arte delicada que brinca perigosamente com as bordas, com os limites. Para viver sua metamorfose é preciso produzir um corpo capaz de suportar o intempestivo, suportar o movimento alucinado das partículas desejantes que arrastam o eu para um mundo de devires, para uma linha de fuga. Sensibiliza-se cada microcélula. Impede-se que o corpo aja por automatismos, até o momento em que o desejo arrebenta a imobilidade e tece seu próprio movimento. Como a aranha, uma das muitas imagens utilizadas por Deleuze para definir o corpo sem órgãos:

Mas o que é um corpo sem órgãos? Também a aranha nada vê, nada percebe, de nada se lembra. Acontece que em uma das extremidades de sua teia ela registra a mais leve vibração que se propaga até seu corpo em ondas de grande intensidade e que a faz, de um salto, atingir o lugar exato. Sem olhos, sem nariz, sem boca, a aranha responde unicamente aos signos e é atingida pelo menor signo que atravessa seu corpo como uma onda e a faz pular sobre a presa [...] O narrador pode ser dotado de uma extrema sensibilidade, de uma prodigiosa 
memória: ele não possui órgãos no sentido em que é privado de todo uso voluntário e organizado de suas faculdades. Em contrapartida, uma faculdade se exerce nele quando é coagida e forçada a fazê-lo; e o órgão correspondente vem situar-se nele, mas como um esboço intensivo despertado pelas ondas que lhe provocam o uso involuntário. Sensibilidade involuntária, memória involuntária, pensamento involuntário são como que reações globais intensas do corpo sem órgãos a signos de diversas naturezas (Deleuze, 1987, p.182-183).

Porém, essa involuntaridade não deve ser confundida com uma passividade frente aos acontecimentos. Ela é uma disposição de abertura perante o inacabado, ao improviso, às multiplicidades, às diferenças, aos devires. Na oposição do verbo ser, o devir. Os devires para Gilles Deleuze e Félix Guattari (devir-animal, devir-mulher, devir-invisível, devir-molécula etc.) são linhas de fuga que desfazem as essências e as significações em proveito de uma matéria mais intensiva onde se movimentam os afetos. Ultrapassar um limiar atingir um continuum de intensidades que não valem mais do que por elas mesmas, encontrar um mundo de intensidades puras, onde todas as formas se desfazem em proveito de uma matéria não formada de fluxos desterritorializados, de signos assignificantes (Deleuze; Guattari, 1977, p. 20).

Devir é estabelecer uma linha de aproximação com aquilo com o qual devimos, é uma dupla captura, na qual cada uma das formas que são aproximadas são arrastadas para longe de suas essências, de forma que se estabelece uma indistinção entre a forma desterritorializada e a desterritorializante.

Devir é a partir das formas que temos, do sujeito que somos, dos órgãos que possuímos e das funções que cumprimos, extrair partículas entre as quais instauramos aproximações de movimento e repouso, de velocidade e lentidão, as mais próximas daquilo que estamos para nos tornar e através da quais nos tornamos. É nesse sentido que o devir é processo do desejo (Deleuze; Guattari, 1980, p. 334).

Essa disposição ao inacabado, longe de ser signo da falta, é a possibilidade da invenção de novas formas subjetivas. É nela que encontramos a figura da mulher, descrita por Clarice Lispector como sendo "uma qualidade de matéria-prima, alguma coisa que podia vir a definir-se, mas que jamais se realizara, porque sua essência era de "tornar-se"" (Lispector, 1980,p.132).

Essa compreensão é que também leva Deleuze e Guattari a dizerem que devir-mulher é a chave de todos os outros devires. Ora se todos os devires já são moleculares, compreende-se aí o devir-mulher, é preciso dizer também que todos os devires começam e passam pelo devir-mulher. É a chave dos outros devires (Deleuze; Guattari, 1980, p.340).
Mais que uma divisão do mundo entre homens e mulheres, uma demarcação rígida dos territórios do gênero masculino e do feminino, o que parece estar em jogo é um certo modo diferente de vivenciar os corpos. Ser mulher implica aqui em criar um corpo em abertura ao inacabado, ao impreciso, um corpo aberto a todos os outros devires que o possam povoar: devir animal, devir-vegetal, devir-máquina, devir-molécula. Independente do gênero a que pertencem os personagens, eles podem ser atingidos por este movimento, aliás é a condição para viverem sua desterritorialização.

\footnotetext{
...nem imitar nem tomar a forma feminina, mas emitir partículas que entram em aproximação de movimento e repouso, ou na zona de vizinhança de uma microfeminidade, isto é, produzir em nós mesmos uma mulher molecular, criar a mulher molecular. Nós não queremos dizer que uma tal criação seja exclusividade do homem, mas ao contrário, que a mulher como entidade molar tem que tornar-se mulher para que o homem também se torne ou possa tornar-se (Deleuze; Guattari, 1980, p. 338).
}

Porém, fica mais claro quando pensamos que ser mulher não é uma essência, mas um devir. Devir-mulher é algo a ser produzido mesmo pelo indivíduo do gênero feminino. Ser mulher é uma forma de vivenciar o corpo, uma primeira aprendizagem antes de se tornar um inventor de metamorfoses. Um espaço em permanente deslocamento entre sexos e entre gêneros.

Longe de um dualismo entre homem-mulher, a figura do andrógino presente na leitura que Deleuze faz da Recherche de Proust pode nos dar uma idéia mais aproximada deste movimento:

Em cada indivíduo que traz em si os dois sexos 'separados por um compartimento' devemos intervir um nebuloso conjunto de oito elementos, em que a parte masculina ou a parte feminina de um homem ou de uma mulher pode relacionar-se com a parte feminina ou a parte masculina de uma outra mulher ou de um outro homem (dez combinações para os oito elementos) (Deleuze, 1987, p.176).

O andrógino abre aqui não só a possibilidade de tornar-se mulher como de criar $n$ sexos diferentes, $n$ combinações diferentes. O narrador andrógino abre assim um campo maior de possibilidades, cria uma zona intermediária que destrói a constituição de uma estrutura binária do tipo homem-mulher. E é justamente nesse espaço intermediário que passa o devir, ele nunca é um começo, nem um fim, ele está sempre em processo de tornar-se.

Mas uma linha de devir não tem começo nem fim, nem partida nem chegada, nem origem nem destino; 
e falar de ausência de origem, colocar a ausência de origem na origem é um mau jogo de palavras. Uma linha de devir tem somente um meio. O meio não é uma média, é uma aceleração, é a velocidade absoluta do movimento. Um devir está sempre no meio, nós não o podemos colocar senão no meio. Um devir não é um nem dois, nem aproximação dos dois, mais entre-dois, fronteira ou linha de fuga, de queda, perpendicular aos dois. Se o devir é um bloco (blocolinha), é porque ele constitui uma zona de vizinhança e indiscernibilidade, um no man's land, uma relação não localizável envolvendo os dois pontos distantes ou contíguos, colocando um na vizinhança do outro e a vizinhança-fronteira é indiferente à contigüidade como à distância (Deleuze; Guattari, 1980, p.360).

Assim, essas experimentações do corpo não seguem uma linha evolutiva, sem começo, nem fim, pois, como ressalta Deleuze, o devir é sempre processo, nem começo nem fim da viagem, mas justamente o meio, um espaço intermediário que rompe com todas as identidades, com todas as oposições binaristas. Um devir não se rege por proposições excludentes como: ou homem ou mulher, ou criança ou adulto, ou humano ou inumano, ou orgânico ou inorgânico, é regido pela conjunção aditiva: ser homem e ser mulher, ser criança e ser adulto ser inumano e ser inumano ser orgânico e ser inorgânico. Infinitas séries percorrendo o corpo vivendo a multiplicidade de outros que a mediocridade de uma única vida não comporta. Um mundo perpassado de novas potencialidades ontogenéticas, novas estéticas da existência, um cenário com os mais diversos seres que ecoam por uma nova arte da existência .

No entanto o que poderia o olhar do cartógrafo esquizoanalista ainda descortinar sobre a política dos corpos, gênero e sexualidades no cenário do século XXI. Como as contribuições da esquizonálise poderiam fornecer instrumentos para pensarmos novas estratégias de resistência neste cenário?

No plano do visível o olhar do cartógrafo apreende um permanente embate e um espaço bastante confuso entre as identidades sexuais: as reivindicações identitárias dos grupos feministas; as lutas de afirmação dos grupos LGBT (lésbicas, gays, bissexuais e transgêneros ); a invenção das novas formas de masculinidade, a exemplo da figura do metrossexual; a fabricação de novas estéticas do corpo graças às intervenções cirúrgicas, às academias de ginástica, à infinidade de dietas para emagrecer; o apelo midiático à fabricação do corpo eternamente jovem, magro e saudável.

Demarcação de territórios de identidade, importação de formas identitárias produzidas e formatadas pela mídia, onde estariam essas desterritorializações, os devires, a produção permanente de novas formas de existência apregoadas de forma tão otimista pela esquizoanálise?
No entanto a realidade não se reduz ao visível. Como ressalta Rolnik, no plano das micropolíticas o que se capta é a produção do que justamente acaba por desestabilizar as figuras e, junto com isso, o quadro classificatório dos gêneros, sejam eles sexuais, raciais, étnicos ou outros quaisquer (Rolnik, 1998, p. 63). Mais uma vez é no campo das artes que encontramos essas linhas de fuga, essas formas de resistência. O olhar do cartógrafo vai a uma sessão de cinema. A sétima arte que apaixonava Deleuze a ponto de escrever dois livros sobre o tema: Cinema 1: imagem movimento e Cinema 2: A imagem tempo. Provocado pela paixão cinéfila do autor, o olhar do cartógrafo visita um filme de um diretor hispânico, Pedro Almodóvar, que parece captar com bastante profundidade as nuances das transgressões contemporâneas das fronteiras do corpo, dos gêneros e da sexualidade no filme 'Tudo sobre minha mãe'.

Em uma das cenas mais conhecidas do filme, a personagem travesti, chamada Agrado, assume a cena de um palco para, segundo a mesma, contar a história de sua vida. Em seu excelente artigo $O$ exemplo de agrado, o autor Wenceslao Machado de Oliveira Jr., nos traz uma interessante descrição da mesma:

A câmera desliza sobre as cortinas vermelhas fechadas e as luzes se acendem num foco no meio do palco, onde Agrado está de pé. Ela pede desculpas pela ausência das duas atrizes daquela noite dizendo que, aos que não tenham nada mais pra fazer, poderia contar a história de sua vida. Após a saída indignada de algumas pessoas da platéia, Agrado inicia sua fala entre irônica e sarcástica, completada por um gestual ambíguo. "Me chamam Agrado, porque toda minha vida só fiz agradar às pessoas. E, além disso, sou muito autêntica. Olhem que corpo!!”. Faz uma pausa e aí começa a apontar as partes de seu corpo onde as transformações sonhadas por ela se realizaram através de inúmeras intervenções cirúrgicas. A cada parte apontada, corresponde o valor da respectiva cirurgia: "Peitos. Dois, porque não sou nenhum monstro. Oitenta mil cada... mas já bastante amortizados". A cena termina com esta fala de Agrado: "Não devemos economizar, pois se é mais autêntica quanto mais se parece com o que se sonhou para si mesma". Esta seqüência fecha-se com um close no rosto da personagem que ainda mantém seu olhar engraçado, mas que agora também parece esperar a aprovação da platéia. Aplausos (Oliveira Jr., 2005, p. 55-56).

Em seu artigo, o autor destaca que a personagem Agrado não fala do sexo, do seu corpo-intimidade, traz o seu corpo-imagem, fabricado artificialmente, como signo de sua essência, de sua mais verdadeira autenticidade, contrastando com a produção da subjetividade na modernidade que tem na imagem do corpo físico um de seus pontos centrais. Pois a noção de autenticidade está em nossa cultura vinculada à idéia de persistência e permanência das nossas origens - biológicas 
e psicológicas - ao longo da vida. É ela, por exemplo, que produz a cadeia de linearidade que fabricará nossas identidades sexuais e de gênero.

No entanto, Agrado, ao invés de se prender a sua identidade sexual biológica que lhe faz pertencer a espécie dos machos, ou a construção cultural do papel masculino associado a essa identidade biológica, ao contrário, depois de enumerar as intervenções cirúrgicas que tornaram o seu corpo, antes próximo da imagem do masculino, um corpo agora conectado à imagem do feminino, afirma justamente que todas essas intervenções corporais foram feitas com o intuito de apresentá-la como uma imagem autêntica. "Uma autenticidade que vincula os (corpos de) homens e mulheres não mais (e somente) à natureza, mas especialmente à história e à cultura" (Oliveira Jr., 2005, p. 58). Podemos acrescentar, ao devir, à capacidade de reinvenção e transformação (graças às modernas tecnologias) de um dos últimos redutos do sujeito monolítico: o corpo biológico.

As provocações do diretor não terminam na desconstrução do corpo biológico, mas também, ironicamente, das novas representações de gênero emergentes das transformações da modernidade. Como ressalta Oliveira Jr.:

O próprio título do filme, Tudo sobre minha mãe, é uma ironia sobre nossas concepções de maternidadepaternidade, uma vez que nomeia uma história sobre a mãe para nos falar no pai. Melhor dizendo, o diretor consegue uma tensão entre os papéis representativos de "pai" e "mãe", mediante uma apresentação ambígua das imagens de mulher e homem - fazendo eco, tal proposição, numa sociedade em que a imagem e a cultura têm superado, em muitas e variadas situações, a biologia e a natureza (Oliveira Jr., 2005, p. 61).

Podemos acrescentar a essa análise que o filme é também uma das citações do filme All about Eve, que as personagens da mãe e do adolescente aparecem vendo no início, filme no qual a personagem central perde lugar para a personagem secundária, brilhantemente interpretada por Bette Davis. No filme de Almodóvar, há também um deslocamento da personagem principal, pois é um filme para falar da mãe, que, no entanto, passa o filme todo na busca do pai genitor de seu filho, um homem chamado Esteban, que como Agrado, também tornou-se um personagem transgênero, Lola. Assim, o diretor brinca o tempo todo desconstruindo nossas expectativas e também nos convidando a visitar as margens, as bordas, as fronteiras do desejo. Na memória do espectador ficam as personagens transgêneros de Agrado e Lola. Assim, talvez não seja exagero dizer que o principal personagem do filme seja o próprio desejo, lembrando também o título da peça de Tennesse Williams, Um bonde chamado Desejo, que a personagem Huma Rojo aparece encenando no filme de Almodó- var. Nos lembra também um dos primeiros filmes do diretor, A lei do desejo, que ao contrário do que se espera do título, encena também um desejo sem lei, um desejo que transgride todas as fronteiras sexuais e de gênero.

Se Agrado e Lola tornam-se as principais imagens do filme, é porque, ao contrário do que poderia supor o título do filme, o desejo encenado aqui não é o desejo do teatro edípico, mas um desejo transgênero encenando no final do filme as probabilidades menos esperadas: Lola, um pai travesti engravidando duas mulheres ou mesmo a ligação amorosa entre a personagem lésbica, Huma Rojos, e a personagem travesti, Agrado. É porque, lembrando Deleuze e Guattari (1976, p. 94), a realidade molecular do desejo é transsexual, no sentido em que desafia as constituições binárias do sexo. Ou mesmo na análise histórica que os autores fazem em Mil Platôs sobre os rituais de travestismo nas sociedades primitivas:

Os ritos de travestismo, de travestimento, nas sociedades primitivas onde o homem torna-se mulher, não se explicam nem por uma organização social que faria corresponder relações dadas, nem por uma organização psíquica que faria com que o homem desejasse ser mulher tanto quanto a mulher ser homem. A estrutura social, a identificação psíquica deixam de lado demasiados fatores especiais: o encadeamento, a precipitação e a comunicação de devires que o travesti desencadeia [...] É a mesma coisa para a sexualidade: esta se explica mal pela organização binária dos sexos, e não se explica melhor por uma organização bissexuada de cada um dos dois. A sexualidade coloca em jogo devires conjugados demasiadamente diversos que são como $n$ sexos, toda uma máquina de guerra pela qual o amor passa (Deleuze; Guattari , 1997, p. 71, v.4).

Nesses meandros, tecem-se a linhas de resistência tão apregoadas pela esquizoanálise, pois o cinema parece acenar com novas possibilidades de composição das subjetividades contemporâneas, afetando até mesmo a construção monolítica e essencialista das identidades que buscam seu fundamento na biologia. No lugar das constituições molares das políticas identitárias sexuais e de gênero, o olhar oblíquo da esquizoanálise vê também no plano molecular um desejo que está sempre fugindo por todos os lados, produzindo novas conexões, aproximando as relações mais improváveis.

No entanto não seria isso mesmo a função do cinema? Pois, provocativamente, nas palavras de Félix Guattari:

nas piores condições comerciais, ainda se podem produzir bons filmes, filmes que modifiquem as combinações de desejo, que destruam os estereótipos, que nos abram o futuro, que, já há muito tempo, não existem mais boas sessões de psicanálise, nem boas descobertas, nem bons livros psicanalíticos (Guattari, 1980, p. 117). 
Pois a ilusão não está nas imagens de cinema: a ilusão consiste em crer que existe um sujeito, um sujeito único e autônomo correspondendo a um indivíduo, quando o que está em jogo é sempre uma multidão de modos de subjetivação e de semiotização (Guattari, 1980, p. 112).

Portanto, o desafio da esquizoanálise é a produção permanente de novas formas de nos relacionarmos com nossos eus, uma espécie de identidade nômade em um circuito de metamorfoses sem fim. Ao invés da compartimentalização em saberes, em gêneros, em identidades, em estruturas binaristas oponentes, um exercício constante de pulverização, de multiplicação das diferenças, buscando sempre trânsitos livres na busca de novas conexões infinitas. Ver-se de novos modos, dizer-se de novas maneiras, estranhar a imagem refle- tida no espelho que recorta nossas infinitas possibilidades, recusar toda miragem de identidade que nos torna limitados. O desafio de uma experimentação que leve em conta não identidades, mas devires, não retrospectros do passado, mas o próprio presente. Ensaiar novas formas de subjetividade, novas estéticas da existência.

A tarefa da esquizoanálise é desfazer incansavelmente nossos egos e seus pressupostos, libertar as singularidades pré-pessoais que eles encerram e recalcam, fazer escorrer os fluxos que eles seriam capazes de emitir, de receber ou de interceptar, estabelecer sempre mais finalmente as esquizas e os cortes, bem acima das condições de identidade, montar as máquinas desejantes que recortam cada um e o agrupam com outros (Deleuze; Guattari, 1976, p. 460).

\title{
Referências
}

CARROLL, L. Alice no país das maravilhas. Alice no país do espelho. São Paulo: Abril Cultural, 1972.

DELEUZE, G. Conversaçoes. Rio de Janeiro: Editora 34, 1992. . Crítica e clínica. São Paulo: Editora 34, 1997.

Proust e os signos. Rio de Janeiro: Forense

Universitária, 1987.

DELEUZE, G; GUATTARI, F. O Anti Édipo. Rio de Janeiro: Imago, 1976.

Kafka: Por uma literatura me-

nor. Rio de Janeiro: Imago, 1977.

Mil Platôs: capitalismo e esqui-

zofrenia. Rio de Janeiro: Editora 34, 1996, v.3. Mil Platôs: capitalismo e esqui-

zofrenia. Rio de Janeiro: Editora 34, 1997, v.4. Mille Plateaux: Capitalisme et

schizophrénie. Paris: Minuit, 1980.

FERREIRA, A.B.H. Novo dicionário da língua portuguesa. Rio de Janeiro: Nova Fronteira, 1986.
GUATTARI, F. Caosmose: um novo paradigma estético. Rio de Janeiro: Editora 34, 1992.

. O divã do pobre. In: METZ, C. (Org.). Psicanálise e cinema. São Paulo: Global, 1980. p.105-117.

LISPECTOR, C. Perto do coração selvagem. São Paulo: Circulo do Livro, 1980.

MACHADO, R.Deleuze e a filosofia. Rio de Janeiro: Graal, 1990.

OLIVEIRA JR. W.M. O exemplo de Agrado: imagem, técnica e autenticidade. Educar em revista, v. 26 n. 1, Campinas, p. 53-65, 2005.

PEIXOTO, N. B. O olhar do estrangeiro. In: NOVAES, A.(Org.). O olhar. São Paulo: Cia. das Letras, 1988. p. 361-365. ROLNIK, S. Cartografia sentimental: transformações contemporâneas do desejo. São Paulo: Estação Liberdade, 1989.

Tristes gêneros. In: LINS, D. (Org.). A dominação masculina revisitada. Campinas: Papirus, 1998. p.63-68..

\section{The Schizoanalysis: an Oblique Look on Bodies, Genders and Sexualities}

\begin{abstract}
This work presents some concepts of Schizoanalysis, a theory produced by Gilles Deleuze and Felix Guattari to analyze some of contemporary cartographies about the new aesthetics of body, gender and sexuality. The Schizoanalysis's project presents the challenge of the deconstruction of monolithic models of subjectivity to produce a new aesthetics of subjectivicty and new semiotics that could reinvent our relationship with ourselves and the other in the composition of new existing territories. The challenge of an experimentation that does not take identities into consideration, but becomings; it also does not take retrospect of the past into consideration, but the present itself so as to practice new forms of subjectivity, new aesthetics of existence.
\end{abstract}

Key words: schizoanalysis; body; gender; sexuality.

Data de recebimento do artigo: 23-06-2008

Data de aprovação do artigo: 14-11-2008 